This is the manuscript of a published paper. It should be cited as:

Evans, A W (2011). Fatal accidents at railway level crossings in Great Britain 1946-2009. Accident

Analysis and Prevention 43(5), 1837-1845.

\title{
FATAL ACCIDENTS AT RAILWAY LEVEL CROSSINGS IN GREAT BRITAIN 1946-2009
}

\author{
Andrew W Evans \\ Imperial College London \\ Revised: February 2011
}

\begin{abstract}
Summary
This paper investigates fatal accidents and fatalities at level crossings in Great Britain over the 64-year period 1946 to 2009. The numbers of fatal accidents and fatalities per year fell by about 65 per cent in the first half of that period, but since then have remained more or less constant at about 11 fatal accidents and 12 fatalities per year. At the same time other types of railway fatality have fallen, so level crossings represent a growing proportion of the total. Nevertheless, Britain's level crossing safety performance remains good by international standards.

The paper classifies level crossings into three types: railway-controlled, automatic, and passive. The safety performance of the three types of crossings has been very different. Railway-controlled crossings are the best-performing crossing type, with falling fatal accident rates. Automatic crossings have higher accident rates per crossing than railway controlled or passive crossings, and the accident rates have not decreased. Passive crossings are by far the most numerous, but many have low usage by road users. Their fatal accident rate has remained remarkably constant over the whole period at about 0.9 fatal accidents per 1000 crossings per year.
\end{abstract}

A principal reason why fatal accidents and fatalities have not fallen in the second half of the period as they did in the first half is the increase in the number of automatic crossings, replacing the safer railway controlled crossings on some public roads. However, it does not follow that this replacement was a mistake, because automatic crossings have advantages over controlled crossings in reducing delays to road users and in not needing staff.

Based on the trends for each type of crossing and for pedestrian and non-pedestrian accidents separately, in 2009 a mean of about 5 per cent of fatal accidents were at railway controlled crossings, 52 per cent were at automatic crossings, and 43 per cent were at passive crossings. Fatalities had similar proportions. About 60 per cent of fatalities were to pedestrians.

A simple comparison of automatic railway level crossings and signalised road intersections found that in 2005 the numbers of fatalities per 1,000 crossings or intersections were similar.

\section{Keywords}

Railways, roads, level crossings, safety, accidents, fatalities.

Centre for Transport Studies

Department of Civil and Environmental Engineering

Imperial College London

London SW7 2AZ e-mail: a.evans@imperial.ac.uk

Tel: 02075946043

Fax: 02075946102 


\section{Introduction}

This paper investigates the safety performance of railway level crossings in Great Britain over the longterm from 1946 to 2009. A reason for concern about level crossings is that their safety performance is not improving, or improving only slowly. The lower curve in Figure 1 is a simple plot of the average number of fatalities per year at level crossings in Great Britain in five-year intervals from 1946 to 2009. The number of fatalities per year fell substantially in the first half of this period from 42.6 in 1946-1950 to 11.8 in 1971-1975, but it has remained more or less constant since then, and was 10.8 in 2006-2009. At the same time, other railway fatalities have fallen, so level crossing fatalities are becoming more prominent and represent an increasing proportion of the total. The 42.6 level crossing fatalities per year in 1946-1950 represented 11 percent of all railway fatalities (excluding trespassers and suicides), but the 10.8 level crossing fatalities per year in 2006-2009 represented 46 per cent of all railway fatalities. Good quality data on level crossing numbers, fatalities and fatal accidents are available for Great Britain since 1946, and the aim of this paper is to explore what can be learned from a long-term analysis of these data. The paper is confined to fatal accidents and fatalities to avoid complications from changing definitions and under-recording of non-fatal injuries.

Although 95 per cent of fatalities at level crossings are to road users, either pedestrians or road vehicle occupants, the long-term development of level crossing fatalities does not mirror those in road accidents generally. The upper curve in Figure 1 plots the average number fatalities per year in road accidents, not including level crossing accidents, measured in units of 100 . Road fatalities increased in the first half of the period at the time when level crossing fatalities were falling, and decreased in the second half of the period at the time when level crossing accidents were about constant. Another notable difference is that the proportion of fatalities to pedestrians is higher at level crossings than in road accidents generally. (The proportions of fatalities to pedestrians in 1946-2009 were 56 per cent at level crossings, and 36 per cent in other road accidents.) Therefore it seems that the factors influencing level crossing fatalities are different from those influencing road accidents.

This paper is about Great Britain, but it is useful at the outset to place the performance of Great Britain in a European context, using data from the 'Common Safety Indicators' (CSIs) assembled by the European Railway Agency (ERA, 2010). Compared with most other European countries, the United Kingdom (which is Great Britain plus Northern Ireland) has a good record. In 2008, the UK had fewer level crossing (LC) fatalities than France or Germany (14 compared with 42 and 52 respectively), fewer LC fatalities per million population (0.26 compared with 0.65 and 0.67$)$, fewer LC fatalities per 1000 level crossings (2.1 compared with 2.9 and 4.8), fewer LC fatalities per railway route-kilometre ( 0.45 compared with 1.46 and 1.67), and fewer LC fatalities per billion train-kilometres (26 compared with 79 and 50).

The paper continues as follows. Section 2 considers the numbers and types of level crossings in Britain. Section 3 considers fatalities and fatal accidents at level crossings. Section 4 uses a simple statistical model to analyse the data. Section 5 presents the results of the modelling. Section 6 compares fatal accidents and fatalities at automatic level crossings and signalised road intersections in 2005. Section 7 presents conclusions. Appendix 1 gives additional statistical results. 
Figure 1: Level crossing and road fatalities per year in five-year intervals: Great Britain: 1946-2009

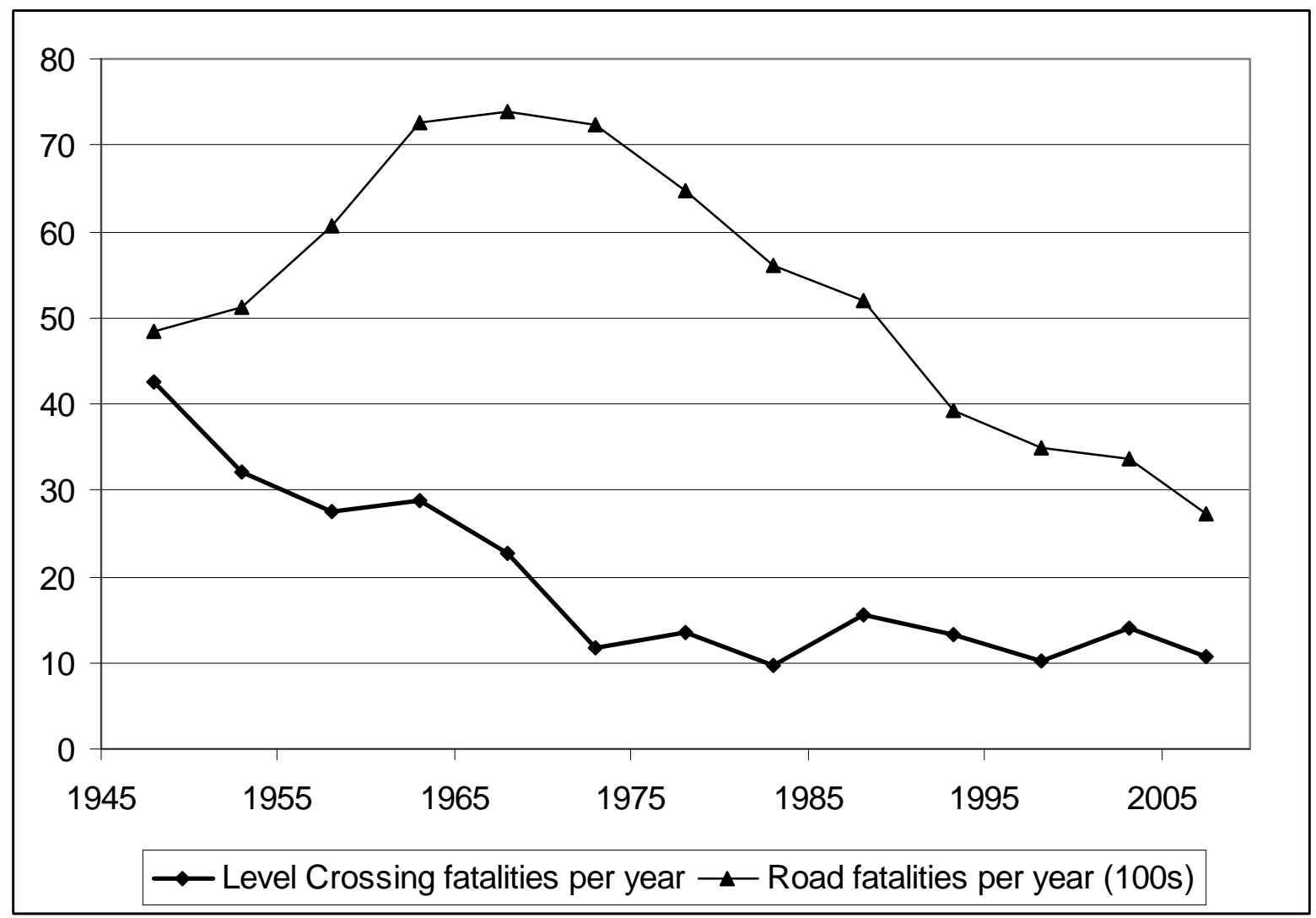

Figure 2: Numbers of level crossings: Great Britain: 1946-2009

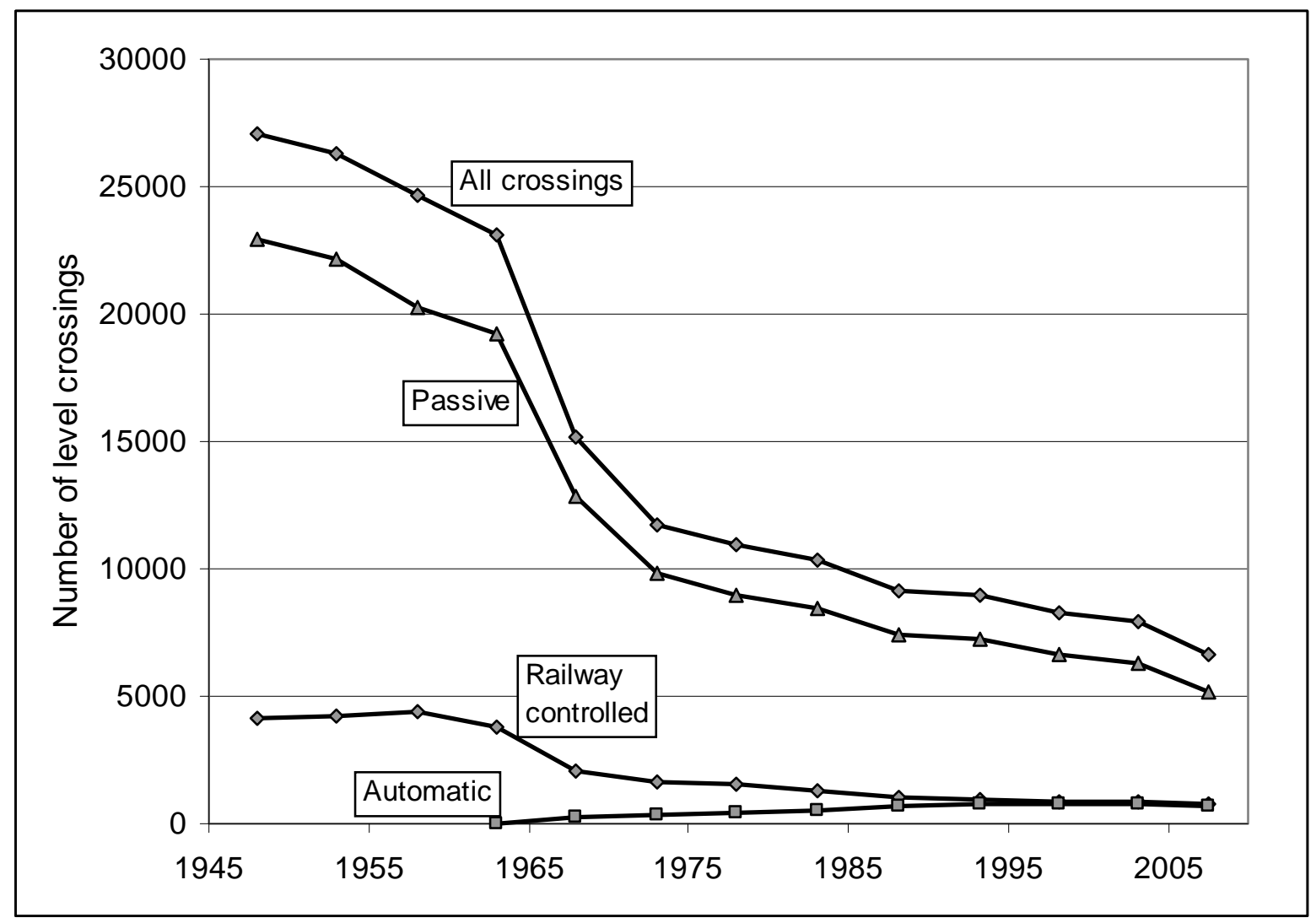




\section{Numbers and types of level crossings}

Table 1: Average number of level crossings in 5-year periods: $\mathbf{1 9 4 6 - 2 0 0 9}$
\begin{tabular}{|lrrrr|}
\hline Period & $\begin{array}{r}\text { Railway } \\
\text { controlled }\end{array}$ & Automatic & Passive & All \\
$1946-1950$ & 4,148 & & 22,902 & 27,050 \\
$1951-1955$ & 4,186 & & 22,124 & 26,310 \\
$1956-1960$ & 4,360 & & 20,298 & 24,658 \\
$1961-1965$ & 3,823 & 14 & 19,225 & 23,062 \\
$1966-1970$ & 2,036 & 220 & 12,884 & 15,141 \\
$1971-1975$ & 1,635 & 307 & 9,820 & 11,762 \\
$1976-1980$ & 1,582 & 394 & 9,004 & 10,980 \\
$1981-1985$ & 1,325 & 523 & 8,475 & 10,323 \\
$1986-1990$ & 1,021 & 729 & 7,379 & 9,129 \\
$1991-1995 / 96$ & 930 & 779 & 7,254 & 8,963 \\
$1996 / 97-2000 / 01$ & 880 & 782 & 6,656 & 8,318 \\
$2001 / 02-2005$ & 865 & 800 & 6,293 & 7,958 \\
$2006-2009$ & 813 & 720 & 5,144 & 6,677 \\
\hline
\end{tabular}

The railway safety regulator in Britain, formerly HM Railway Inspectorate (HMRI) and now the Office of Rail Regulation (ORR), records the numbers and types of level crossings on the national railway system in its annual report (HMRI, annual), and has done so at least since 1946. The official classification of level crossing types has changed over the years: in 1946 there were four types; in recent years there have been twelve. However, they may reasonably be grouped into three broad types, which are used in this paper. These are the following.

(1) Railway-controlled crossings. At these crossings, the opening and closing of the crossing to the railway or the road is controlled by a member of the railway staff, who is a signaller or crossing-keeper. The operation of the crossing is now almost always interlocked with the railway signalling, so that it is not possible to clear the signals for a train unless and until the crossing is closed to the road. Such crossings traditionally had large swinging gates, some of which remain in service. Modern railway-controlled crossings have lifting full barriers, either operated by a signaller at the site, or operated remotely and supervised by Closed Circuit Television.

(2) Automatic crossings. These crossings are operated by the passage of trains without the intervention of railway staff. When a train approaching the crossing reaches a 'strike-in' point, it triggers the operational cycle: first there is a warning to road users; then the crossing is closed to road users; then the train passes; and finally the crossing opens to the road again. The minimum permissible time in Britain between the train striking-in and its reaching the crossing is 27 seconds (Health and Safety Executive, 1996, page 15). The best-known type of automatic crossing is the automatic half barrier (AHB), which has flashing lights and barriers covering only the approach side of the road. The reason for having only half barriers is to provide an escape route for any vehicle or person already on the crossing when the barriers fall. There are various other types of automatic crossing, including some with lights but no barriers.

(3) Passive crossings, including footpath crossings. Some of these are called 'user-worked' crossings in Britain. These crossings have no active warnings of the approach of trains, so that the safety of persons or vehicles crossing depends on their own vigilance and behaviour. Sometimes telephones are provided to enable users to phone the railway signaller to check that the line is clear. Passive crossings account for the great majority of level crossings: they are typically on private roads, on farms, or on footpaths. Many, but not all, are little used; some usage is seasonal or can change with land use. 
Almost all the crossings on public roads are either railway-controlled or automatic. They typically have much higher usage than passive crossings.

Table 1 and Figure 2 show the average numbers of crossings of each type on the main line railway system of Great Britain in 5-year periods over the 64 years 1946-2009 ${ }^{1}$. There were about 27,050 in 1946-1950, and about 6,680 in 2006-2009. The reduction is partly the result of long-term policies to eliminate crossings where possible, and partly because the national railway route length roughly halved during the period. The fastest reduction in the numbers of level crossings occurred in the late 1960s, when many railway routes were closed as a matter of policy (British Railways Board, 1963). The number of crossings per route-km was 0.85 in 1946-1950 and 0.42 in 2006-2009.

Table 1 shows that in 1946-1950 all crossings were either railway-controlled or passive. Automatic crossings were not introduced into Great Britain until the early 1960s, although they were then fairly common elsewhere in Europe (see Ministry of Transport 1968, Section I; Hall and Van der Mark, 2008). The number of railway-controlled crossings steadily declined from about 4,150 in 1946-1950 to 813 in 2006-2009. This was because of a mixture of crossing closures, line closures, and conversions of crossings to automatic. The remaining number of railway-controlled crossings in Britain is high by European standards, many countries having none (Rail Safety and Standards Board, 2006). It will be seen later that railway-controlled crossings are relatively safe, and that may partially account for the good safety record at level crossings in Britain. The number of automatic crossings grew from zero in 1956-1960 to 800 in 2001/02-2005, and fell back to 720 in 2006-2009. The number of passive crossings has steadily declined, from about 22,900 in 1946-1950 to 5,140 in 2006-2009.

\section{Fatalities and fatal accidents at level crossings ${ }^{2}$}

Fatalities to level crossing users and staff are classified and recorded by HMRI in the following four groups.

(1) Pedestrians

(2) Occupants of road vehicles

(3) Railway staff

(4) Railway passengers

In this context railway passengers are those on board trains: people outside trains who are intending to travel or who have travelled are classified as pedestrians.

Table 2 gives the numbers of fatalities at level crossings by 5 -year period in each of these groups. There were a total of 1,252 fatalities in the 64 years, an average 19.6 per year. Of these, $700(56 \%)$ were pedestrians, $487(39 \%)$ were occupants of road vehicles, including two-wheeled vehicles and farm vehicles, $44(4 \%)$ were railway staff, and $21(2 \%)$ were railway passengers. The railway passenger fatalities occurred in just three accidents - at Hixon in 1968, Lockington in 1986 and Ufton Nervet in 2004. The proportion of pedestrian fatalities in Britain may be relatively high by international standards; there are little data on this, but one international example is the USA, where only 18 per cent of road user fatalities at level crossings were pedestrians in 2001 (Mok and Savage, 2005, page 868 ). That may be because of relatively less pedestrian activity in the USA.

\footnotetext{
${ }^{1}$ In fact, as indicated by the row labels, Table 1 and later tables include 10 periods of 5 years, 1 period of $5 \frac{1}{4}$ years, 1 period of $4 \frac{3}{4}$ years and 1 period of 4 years. The $1 / 4$ and $3 / 4$ years arise because HMRI switched its reporting period from calendar years up to 1990 to fiscal years (1 April to $31 \mathrm{March}$ ) from $1991 / 92$ to 2003/04, and back to calendar years in 2005. The changing periods have been taken into account in the calculations of the paper.

${ }^{2}$ It should be noted that there is a slight mismatch between the number of level crossings discussed in section 2 and the numbers of fatalities and fatal accidents in section 3 . The former are confined to the national rail system, but the latter cover all railways. There are a sizeable number of level crossings off the national system, but many of these are on heritage railways and are little used. A small number of the fatalities discussed in section 3 were not on the national system. In the rest of the paper we disregard this distinction.
} 
Table 2: Fatalities at level crossings: all railways: Great Britain: 1946-2009

\begin{tabular}{|lrrrrr|}
\hline Period & Pedestrians & $\begin{array}{r}\text { Occupants } \\
\text { of road } \\
\text { vehicles }\end{array}$ & $\begin{array}{r}\text { Railway } \\
\text { staff }\end{array}$ & $\begin{array}{r}\text { Railway } \\
\text { passengers }\end{array}$ & All \\
$1946-1950$ & 126 & 78 & 9 & 0 & 213 \\
$1951-1955$ & 100 & 59 & 1 & 0 & 160 \\
$1956-1960$ & 70 & 59 & 9 & 0 & 138 \\
$1961-1965$ & 68 & 72 & 4 & 0 & 144 \\
$1966-1970$ & 45 & 52 & 9 & 8 & 114 \\
$1971-1975$ & 37 & 19 & 3 & 0 & 59 \\
$1976-1980$ & 37 & 25 & 5 & 0 & 67 \\
$1981-1985$ & 26 & 23 & 0 & 0 & 49 \\
$1986-1990$ & 40 & 33 & 1 & 8 & 82 \\
$1991-1995 / 96$ & 42 & 24 & 0 & 0 & 66 \\
$1996 / 97-2000 / 01$ & 41 & 10 & 0 & 0 & 51 \\
$2001 / 02-2005$ & 37 & 21 & 3 & 5 & 66 \\
$2006-2009$ & 31 & 12 & 0 & 0 & 43 \\
\hline $1946-2009$ & 700 & 487 & 44 & 21 & 1,252 \\
\hline
\end{tabular}

The HMRI annual reports do not explicitly give the numbers of fatal accidents at level crossings, as distinct from fatalities, but they do mention many individual accidents, especially those with more than one fatality. In a previous project, Evans (2003) identified all multiple-fatality accidents mentioned in HMRI reports, including those at level crossings. If one makes the assumption that all multiple-fatality accidents are explicitly mentioned, it is then possible to deduce the numbers of single-fatality accidents, and hence the total numbers of fatal accidents.

Table 3 shows the results of doing this. The bottom line of Table 3 shows the distribution of fatalities in fatal level crossing accidents in Great Britain in 1946-2009: there were 76 accidents with more than one fatality, from which it is deduced that there were 1,029 single-fatality accidents and 1,105 fatal accidents overall. This implies that the mean number of fatalities per fatal accident was 1.133. The worst accident was in 1947 at Burton Agnes level crossing, on the Hull - Scarborough line, when a train struck an army lorry, with 12 fatalities in the lorry. The second worst accident was in 1968 at Hixon level crossing, on the Colwich - Stoke-on-Trent line, when a train struck a slow-moving road transporter loaded with an electrical transformer, leading to 11 fatalities on the train.

Table 3: Distributions of fatalities in fatal level crossing accidents: Great Britain: 1946-2009

\begin{tabular}{|c|c|c|c|c|c|c|c|c|c|c|c|c|c|c|c|}
\hline & & $\mathrm{Nu}$ & abel & f a & de & & gi & $\mathbf{n}_{\mathbf{I}}$ & nb & of & atal & & & Fatal- & Fats/ \\
\hline & 1 & 2 & 3 & 4 & 5 & 6 & 7 & 8 & 9 & 10 & 11 & 12 & All & ities & Acc \\
\hline Pedestrian accs & 685 & 6 & 1 & & & & & & & & & & 692 & 700 & 1.012 \\
\hline Non-ped. accs & 344 & 43 & 15 & 3 & 1 & 3 & & & 1 & 1 & 1 & 1 & 413 & 552 & 1.337 \\
\hline All accidents & 1029 & 49 & 16 & 3 & 1 & 3 & 0 & 0 & 1 & 1 & 1 & 1 & 1105 & 1252 & 1.133 \\
\hline
\end{tabular}

Multiple-fatality accidents may have fatalities to people in more than one of the four categories above: for example, an accident may cause fatalities both to occupants of road vehicles and to staff or passengers on trains. However, it happens that there have been no accidents in which there were fatalities both to pedestrians and to people in other categories. This makes it possible unambiguously to divide accidents into those with pedestrian fatalities and those with other fatalities, labelled henceforth as 'pedestrian' and 'non-pedestrian' accidents. The great majority of the fatalities of the non-pedestrian accidents are occupants of vehicles (road or rail), but these accidents also include a small number of fatalities to railway staff struck by trains while manually operating gates, especially in the early years. Table 3 shows the distribution of fatalities in the two classes of accident. Almost all 
the pedestrian accidents were single-fatality, and all the most serious accidents were non-pedestrian. Of all fatal accidents, 692 (63\%) were pedestrian and 413 (37\%) were non-pedestrian.

Table 4 shows the numbers of pedestrian and non-pedestrian accidents at each of the three types of crossing in 5-year periods from 1946 to 2009. The right-hand panel of Table 4 shows that the total numbers of accidents per year in both categories fell in the first 30 years 1946-1975, but did not fall much in 1976-2009. The overall numbers of accidents per year are plotted in Figure 4 (below).

Table 5 gives the number of fatal accidents at each type of crossing per year per 1000 crossings. It can be seen that the overall fatal accident rate has not changed very much over time from its long term average of 1.17 accidents per year per 1000 crossings. The accident rate at railway-controlled crossings has fallen; that at passive crossings has remained more or less constant at about 0.9 accidents per year per 1000 crossings; that at automatic crossings is both higher and, if anything, rising over time. Figure 3 shows the data points for each type of crossing.

Table 4: Fatal accidents at level crossings: all railways: Great Britain: 1946-2009

\begin{tabular}{|c|c|c|c|c|c|c|c|c|c|c|c|c|}
\hline \multirow[b]{2}{*}{ Period } & \multicolumn{3}{|c|}{ Railway controlled } & \multicolumn{3}{|c|}{ Automatic } & \multicolumn{3}{|c|}{ Passive } & \multicolumn{3}{|c|}{ All crossings } \\
\hline & Ped & Nped & All & Ped & Nped & All & Ped & Nped & All & Ped & Nped & All \\
\hline 1946-1950 & 47 & 25 & 72 & 0 & 0 & 0 & 79 & 28 & 107 & 126 & 53 & 179 \\
\hline $1951-1955$ & 35 & 9 & 44 & 0 & 0 & 0 & 65 & 41 & 106 & 100 & 50 & 150 \\
\hline $1956-1960$ & 17 & 17 & 34 & 0 & 0 & 0 & 53 & 38 & 91 & 70 & 55 & 125 \\
\hline $1961-1965$ & 26 & 15 & 41 & 0 & 0 & 0 & 42 & 41 & 83 & 68 & 56 & 124 \\
\hline $1966-1970$ & 12 & 7 & 19 & 0 & 4 & 4 & 32 & 36 & 68 & 44 & 47 & 91 \\
\hline $1971-1975$ & 11 & 5 & 16 & 4 & 0 & 4 & 22 & 12 & 34 & 37 & 17 & 54 \\
\hline 1976-1980 & 7 & 6 & 13 & 1 & 7 & 8 & 29 & 13 & 42 & 37 & 26 & 63 \\
\hline 1981-1985 & 2 & 2 & 4 & 3 & 11 & 14 & 21 & 7 & 28 & 26 & 20 & 46 \\
\hline 1986-1990 & 1 & 1 & 2 & 9 & 21 & 30 & 27 & 8 & 35 & 37 & 30 & 67 \\
\hline $1991-1995 / 96$ & 3 & 0 & 3 & 10 & 12 & 22 & 29 & 7 & 36 & 42 & 19 & 61 \\
\hline 1996/97-2000/01 & 4 & 0 & 4 & 8 & 7 & 15 & 27 & 3 & 30 & 39 & 10 & 49 \\
\hline 2001/02-2005 & 5 & 0 & 5 & 15 & 15 & 30 & 16 & 6 & 22 & 36 & 21 & 57 \\
\hline 2006-2009 & 3 & 0 & 3 & 9 & 8 & 17 & 18 & 1 & 19 & 30 & 9 & 39 \\
\hline 1946-2009 & 173 & 87 & 260 & 59 & 85 & 144 & 460 & 241 & 701 & 692 & 413 & 1,105 \\
\hline
\end{tabular}

Table 5: Fatal accidents per year per 1000 crossings: Great Britain: 1946-2009

\begin{tabular}{|lrrrr|}
\hline Period & $\begin{array}{r}\text { Railway- } \\
\text { controlled }\end{array}$ & Automatic & $\begin{array}{r}\text { Passive } \\
\text { crossings }\end{array}$ & All \\
$1946-1950$ & 3.47 & & 0.93 & 1.32 \\
$1951-1955$ & 2.10 & & 0.96 & 1.14 \\
$1956-1960$ & 1.56 & & 0.90 & 1.01 \\
$1961-1965$ & 2.15 & 0.00 & 0.86 & 1.08 \\
$1966-1970$ & 1.87 & 3.63 & 1.06 & 1.20 \\
$1971-1975$ & 1.96 & 2.60 & 0.69 & 0.92 \\
$1976-1980$ & 1.64 & 4.06 & 0.93 & 1.15 \\
$1981-1985$ & 0.60 & 5.35 & 0.66 & 0.89 \\
$1986-1990$ & 0.37 & 7.83 & 0.90 & 1.40 \\
$1991-1995 / 96$ & 0.65 & 5.65 & 0.99 & 1.36 \\
$1996 / 67-2000 / 01$ & 0.91 & 3.84 & 0.90 & 1.18 \\
$2001 / 02-2005$ & 1.22 & 7.89 & 0.74 & 1.51 \\
$2006-2009$ & 0.92 & 5.91 & 0.92 & 1.46 \\
\hline $1946-2009$ & 1.89 & 5.62 & 0.90 & 1.17 \\
\hline
\end{tabular}




\section{Analysis}

The analysis in this paper considers fatal accident rates per 1000 crossings per year and trends in these over time by level crossing type and accident type (pedestrian and non-pedestrian). The analysis does not aim to estimate risks at individual crossings, for which various models have been developed, including Austin and Carson (2002) for the United States and the All Level Crossing Risk Model (ALCRM) (Rail Safety and Standards Board, 2010) for Great Britain. These models are used for informing decisions about which level crossings should be upgraded. The ALCRM has some 200 input variables, including the numbers of trains, road vehicles and pedestrians using the crossing per day.

For this paper we have little data on the usage of crossings, and in any case usage varies greatly from one crossing to another. Nevertheless, in interpreting the results, it is useful to be aware that usage systematically varies between crossing types. The Rail Safety and Standards Board (RSSB 2004, Table 4) gives some useful information on average crossing usage by crossing type, excluding footpath crossings. Their data suggest that for railway-controlled crossings, the average number of trains per day is about 70, the average number of road vehicle users is about 1,200 and the average number of pedestrians is about 160 . For automatic crossings, the average number of trains per day is about 60, the average number of road vehicle users is about 1,000 and the average number of pedestrians is about 80. After making reasonable guesses of the amount of footpath use, the average number of trains at passive crossings is about 55 per day, the average number of road vehicle users is only about 4 , and the average number of pedestrians is about 25 . Therefore the most marked difference in usage is between controlled and automatic crossings on one hand, with an average of 1,000-1,200 road vehicles per day and passive crossings on the other hand, with only 4 road vehicles per day. This is a reflection of the fact that controlled and automatic crossings are generally on public roads, whereas passive crossings are generally on private roads, farms, and footpaths. Passive crossings have low numbers of fatal accidents per crossing per year, as shown in Figure 3, but their low usage implies that they have the highest risk per road vehicle-traverse.

In order to model accident trends by crossing type and accident type, we have fitted the following model to the data in Table 4.

where:

$$
y_{i j t}=\alpha_{i j} c_{i t} \exp \left(\beta_{i j} t\right)
$$

$y_{i j t}$ is the mean number of accidents of type $j$ per year at crossings of type $i$ in year $t$ (measured with $1966=0) ;(i=1,2,3 ; j=1,2)$.

$c_{i t}$ is the number of crossings of type $i$ in year $t$

$\alpha_{i j}$ are parameters measuring the mean number of accidents of type $j$ per year at crossings of type $i$ in year 0 .

$\beta_{i j}$ are parameters measuring the annual proportionate rate of change in the number of accidents of type $j$ per crossing per year at crossings of type $i$.

The model assumes that the mean numbers of fatal accidents at crossings of each type are directly proportional to the numbers of crossings of that type, $c_{i t}$. Following Mok and Savage (2005), we have also investigated fitting the model with accidents assumed proportional to a power of $c_{i t}$, not necessarily equal to 1 , However, for no type of crossing or type of accident was the power significantly different from 1 , so we have retained direct proportionality. This differs from Mok and Savage, who found powers of less than 1 in the USA.

The results in this paper are based on the assumption that the accident data are Poisson-distributed, though because the data are 'overdispersed' for the Poisson distribution we have also explored the use of the negative binomial distribution. Appendix 1 gives results for the negative binomial distribution, corresponding to those given in this section for the Poisson distribution. The use of the negative binomial distribution makes no difference to the results of the statistical tests, and only small differences to the parameter estimates. 
In fitting the model, we have assumed that all the $\alpha_{i j}$ s are different, with no particular structure. We then explore the structure of the trend parameters $\beta$ : in particular we explore whether the trend parameters are different for the different types of crossing and accidents. Table 6 gives the main statistical results and test statistics for variants of the model for estimating these trends. Model variant (a) assumes that the trend $\beta$ is zero for all types of crossings and accidents; variant (b) assumes a common non-zero $\beta$ for all types of crossing and accidents; variant (c) assumes different $\beta$ s for different accident types but not for different crossing types $\left(\beta_{1 j}=\beta_{2 j}=\beta_{3 j}\right)$; variant (d) assumes different $\beta$ s for different crossing types but not for different accident types $\left(\beta_{\mathrm{i} 1}=\beta_{\mathrm{i} 2}\right)$; variant (e) assumes that all six $\beta$ s are different.

The scaled deviance in Table 6 is the measure of goodness of fit of the model variants to the data; a large scaled deviance indicates a poor fit. If the data are indeed generated in the way presumed in the model (that is Poisson-distributed with a time-dependent mean), the scaled deviance would be approximately $\chi^{2}$-distributed with mean equal to the number of degrees of freedom. It can be seen that the fit is not good for any of the variants: the data are 'overdispersed'. To test whether one variant of the model fits the data significantly better than another, we compare the difference in the scaled deviances of the two variants with the $\chi^{2}$-distribution with degrees of freedom equal to the difference in degrees of freedom between the variants. For example, variant (e) fits significantly better than variant (d) because the reduction in the scaled deviance of 20.0 in moving from (d) to (e) is larger even that the upper $0.1 \%$ point of the $\chi^{2}$-distribution with 3 degrees of freedom (which is 16.27). On the basis of such tests, variant (e) is significantly the best-fitting model, indicating that the trends are different for each combination of crossing type and accident type. In the work below we adopt model (e), and estimate the mean numbers of accidents per crossing as the sum of those to pedestrians and non-pedestrians.

Table 6: Statistical results from fitting log-linear models to the accident data

\begin{tabular}{|c|c|c|c|}
\hline $\begin{array}{l}\text { Variant of } \\
\text { model }\end{array}$ & $\begin{array}{l}\text { Degrees of } \\
\text { freedom }\end{array}$ & $\begin{array}{c}\text { Scaled } \\
\text { deviance }\end{array}$ & $\begin{array}{l}\text { Estimate of trend parameter (standard error in } \\
\text { brackets) }\end{array}$ \\
\hline (a) No trend & 66 & 171.4 & Assumed zero for all types of crossing and accidents \\
\hline $\begin{array}{l}\text { (b) Common } \\
\text { trend }\end{array}$ & 65 & 162.2 & $-0.57 \%(0.19 \%)$ pa for all types of crossing and accidents \\
\hline $\begin{array}{l}\text { (c) Separate } \\
\text { trends for } \\
\text { accident types }\end{array}$ & 64 & 147.6 & $\begin{array}{l}-0.05 \%(0.23 \%) \text { pa for pedestrian accidents } \\
-1.59 \%(0.33 \%) \text { pa for non-pedestrian accidents }\end{array}$ \\
\hline $\begin{array}{l}\text { (d) Separate } \\
\text { trends for LC } \\
\text { types }\end{array}$ & 63 & 132.2 & $\begin{array}{l}-2.58 \%(0.47 \%) \text { pa for railway-controlled crossings } \\
+1.34 \%(0.77 \%) \text { pa for automatic crossings } \\
-0.19 \%(0.22 \%) \text { pa for passive crossings }\end{array}$ \\
\hline $\begin{array}{l}\text { (e) Separate } \\
\text { trends for LC } \\
\text { types and } \\
\text { accident types }\end{array}$ & 60 & 112.2 & $\begin{array}{l}-2.17 \%(0.55 \%) \text { pa for peds at controlled crossings } \\
-3.50 \%(0.89 \%) \text { pa for non-peds at controlled crossings } \\
+3.49 \%(1.30 \%) \text { pa for peds at automatic crossings } \\
+0.00 \%(0.97 \%) \text { pa for non-peds at automatic crossings } \\
+0.37 \%(0.26 \%) \text { pa for peds at passive crossings } \\
-1.39 \%(0.41 \%) \text { pa for non-peds at passive crossings }\end{array}$ \\
\hline
\end{tabular}

Conclusions from the modelling in Table 6 on the trends in fatal accidents per crossing per year are the following.

- Taken together, fatal accidents per crossing per year show a significant downward trend, but the trend is small, especially compared with other long-term improvements in rail safety (see, for example, Evans 2007).

- The trend for pedestrian accidents per crossing per year taken together is significantly worse than that for non-pedestrian (mostly road vehicle) accidents 
- The trend in accidents per crossing per year is significantly downward at railway-controlled crossings, about flat at passive crossings, and non-significantly upward (as well as higher) at automatic crossings.

Figure 3 plots the modelled and observed numbers of fatal accidents per crossing per year by type of crossing. The observed data are from Table 5. The modelled curves are the sum of those for pedestrian and non-pedestrian accidents from model variant (e). The figure clearly illustrates the different trends for the different types of crossing.

The following are plausible explanations for the different levels and trends in fatal accidents per crossing per year.

- On railway-controlled crossings, the accident rates have declined. This may be first because the methods of operating the crossings have improved: in particular, barriers have replaced many gates, some of which require staff to go on to the tracks. Secondly, the protection offered by the railway signalling systems, which are interlocked with the crossings, has improved, just as railway signalling has improved generally.

- On automatic crossings accident rates are higher than on railway-controlled crossings and have not declined, even though the average crossing usage is broadly similar. Accidents rates are higher because the primary responsibility for the safe operation of automatic crossings rests with road users in observing the warnings indicating approaching trains. Furthermore, if there is a mishap, such as a road vehicle stalling or a pedestrian falling on the crossing, the users are not protected by the railway signals as they are at railway-controlled crossings.

- The safe operation of passive crossings also depends on the vigilance and use of correct procedures by road and footpath users. However, their accident rate per crossing is much lower than for automatic crossings, primarily because, not being on public roads, their usage is lower. However, their accident rate has not declined: it is a remarkable empirical finding in Figure 3 and Table 5 that the fatal accident rate has remained about constant at 0.9 per year per 1,000 passive crossings over the whole period of 64 years, despite investigations to improve them (Rail Accident Investigation Branch, 2009). 
Figure 3: Fatal accidents per 1000 crossings: 1946-2009

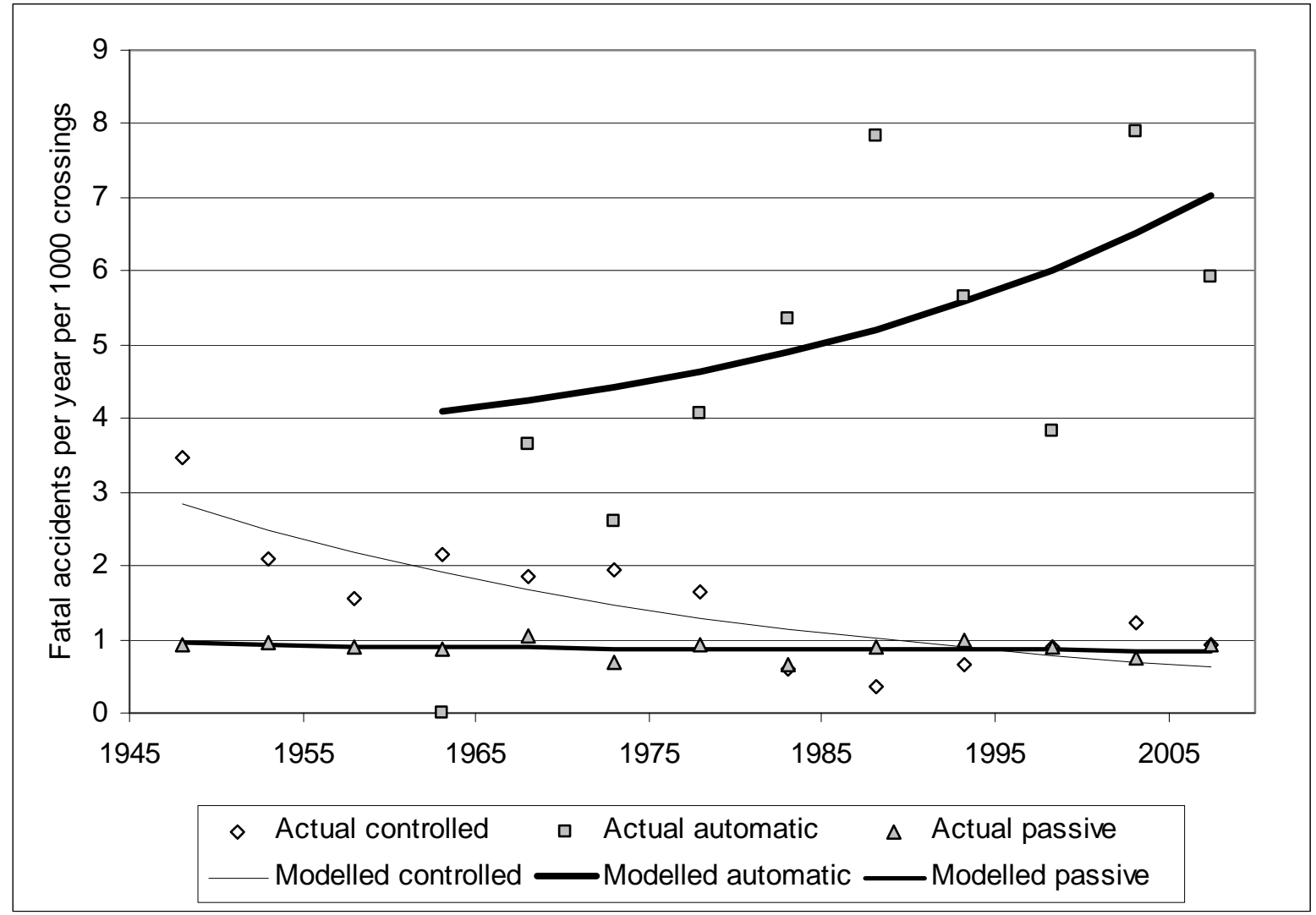

Figure 4: Fatal accidents per year at level crossings: 1946-2009

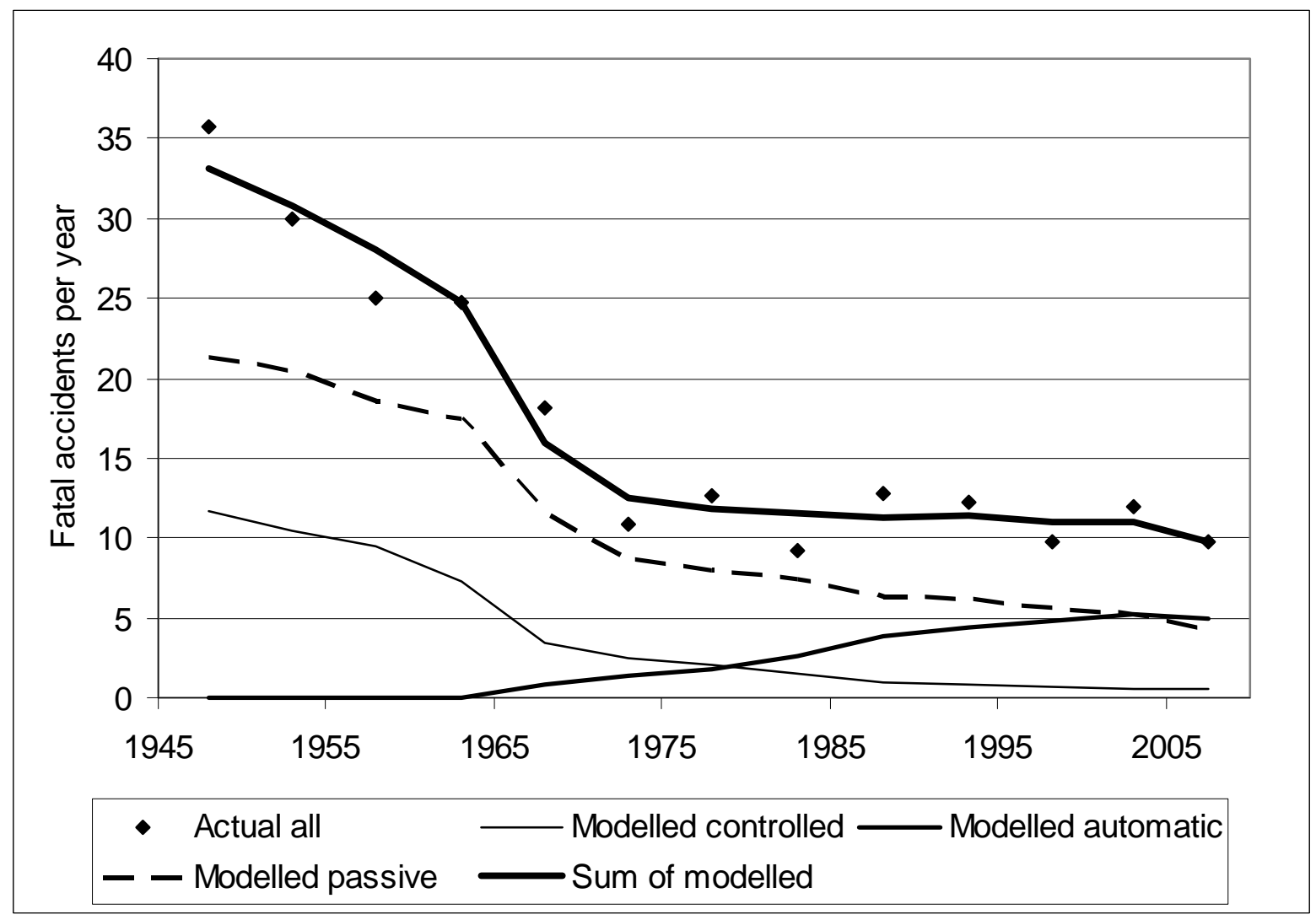


As an extension to fitting model (1) to the accident data, we explored adding further explanatory variables to supplement or replace the time trend. Variables tested were train-kilometres per routekilometre (as an indicator of the intensity of trains), road motor vehicle-kilometres (as an indicator of the intensity of road traffic), and road fatalities per year (as an indicator of general road safety performance). We have not found convincing relationships between accidents per crossing and these variables. Some reasons may be the following. First, as noted above and shown in Figure 3, the safety performance and trends of the different crossing types have been different, so one might not expect accidents per crossing to be well modelled by general variables such as those above. Secondly, a majority of the level crossing accidents are to pedestrians, but variables related to traffic and road accidents are dominated by motor vehicles. Thirdly, there is an interesting argument put forward by Stott (1986) and again by Heavisides and Barker (2008) and by RSSB (2010) that one should not expect a linear relationship between motor vehicle accidents and road traffic flow at automatic level crossings. Rather, the relationship is gamma-shaped, in which accidents rise linearly with traffic at low flows, but then reach a maximum and fall off at higher flows. This is because after a train has initiated the crossing sequence, at high road traffic flows the first road vehicle to arrive is likely to arrive before the train; it then stops and its presence to some degree protects later road vehicles against colliding with the train. At lower road traffic flows, it is more likely that the first vehicle arrives at the same time as the train, with greater risk of collision.

\section{Mean accidents and fatalities per year}

Figure 4 plots the results of combining the modelled trends in accidents per crossing from Figure 3 with the numbers of crossings in Table 1 and Figure 1 to give the modelled trends in fatal accidents per year by type of crossing and in total. Figure 4 also shows the overall observed numbers of fatal accidents per year from the data in Table 4 .

Table 7: Modelled fatal accidents and fatalities: Great Britain 2009

\begin{tabular}{|c|c|c|c|c|c|c|c|}
\hline $\begin{array}{l}\text { Type of } \\
\text { crossing }\end{array}$ & $\begin{array}{l}\text { Type of } \\
\text { fatal } \\
\text { accident }\end{array}$ & $\begin{array}{r}\text { Average } \\
\text { rate of } \\
\text { change in } \\
\text { fatal } \\
\text { accidents } \\
\text { per crossing }\end{array}$ & $\begin{array}{r}\text { Estimated } \\
\text { mean fatal } \\
\text { accidents } \\
\text { per } 1000 \\
\text { crossings } \\
2009\end{array}$ & 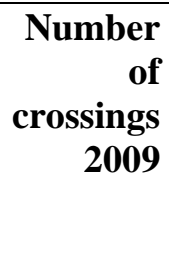 & $\begin{array}{r}\text { Estimated } \\
\text { mean fatal } \\
\text { accidents } \\
\text { per year } \\
2009\end{array}$ & $\begin{array}{r}\text { Fatalities } \\
\text { per fatal } \\
\text { accident }\end{array}$ & $\begin{array}{r}\text { Estimated } \\
\text { mean } \\
\text { fatalities } \\
\text { per year } \\
2009\end{array}$ \\
\hline $\begin{array}{l}\text { Railway } \\
\text { controlled }\end{array}$ & $\begin{array}{l}\text { Pedest- } \\
\text { rian }\end{array}$ & $-2.2 \%$ p.a. & 0.47 & 808 & 0.38 & 1.01 & 0.39 \\
\hline $\begin{array}{l}\text { Railway } \\
\text { controlled }\end{array}$ & $\begin{array}{l}\text { Non-ped- } \\
\text { estrian }\end{array}$ & $-3.5 \%$ p.a. & 0.13 & 808 & 0.10 & 1.34 & 0.14 \\
\hline $\begin{array}{l}\text { Railway } \\
\text { controlled }\end{array}$ & All & & & & 0.48 & & 0.52 \\
\hline Automatic & $\begin{array}{l}\text { Pedest- } \\
\text { rian }\end{array}$ & $+3.5 \%$ p.a. & 3.92 & 717 & 2.81 & 1.01 & 2.84 \\
\hline Automatic & $\begin{array}{l}\text { Non-ped- } \\
\text { estrian }\end{array}$ & $0.0 \%$ p.a. & 3.32 & 717 & 2.38 & 1.34 & 3.18 \\
\hline Automatic & All & & & & 5.19 & & 6.03 \\
\hline Passive & $\begin{array}{l}\text { Pedest- } \\
\text { rian }\end{array}$ & $+0.4 \%$ p.a. & 0.68 & 5,067 & 3.44 & 1.01 & 3.49 \\
\hline Passive & $\begin{array}{l}\text { Non-ped- } \\
\text { estrian }\end{array}$ & $-1.4 \%$ p.a. & 0.17 & 5,067 & 0.87 & 1.34 & 1.16 \\
\hline Passive & All & & & & 4.31 & & 4.64 \\
\hline All types & $\begin{array}{l}\text { Pedest- } \\
\text { rian }\end{array}$ & & & 6,592 & 6.64 & 1.01 & 6.72 \\
\hline All types & $\begin{array}{l}\text { Non-ped- } \\
\text { estrian }\end{array}$ & & & 6.592 & 3.35 & 1.34 & 4.47 \\
\hline All types & All & & & & 9.99 & & 11.19 \\
\hline
\end{tabular}


Table 7 shows modelled trends, accident rates per thousand crossings, numbers of crossings, modelled numbers of accidents, and estimated fatalities in 2009. The estimated numbers of fatalities per fatal accident are assumed to be different for the two types of accident, and constant over time. They are taken from Table 3.

Conclusions from Figure 4 and Table 7 are the following.

- The estimated mean numbers of fatal accidents and fatalities at level crossings in 2009 were 10.0 and 11.2 respectively. (The actual numbers in that year were 11 and 13 respectively, but there is considerable variation from year to year.)

- At railway-controlled crossings the number of fatal accidents per year has fallen greatly over the long term, and had reached low levels in 2009. The fall is partly because the number of such crossings has fallen (shown in Table 1 and Figure 2), and partly because the accident rate has fallen (shown in Figure 3 and discussed in Section 4). Railway-controlled crossings are estimated to have accounted for a mean of only about $5 \%$ of level crossing fatal accidents and fatalities in 2009. Most of these are pedestrians.

- At automatic level crossings the number of fatal accidents per year has risen over the long term. This is partly because of the increase in the numbers of such crossings since their introduction in the early 1960s, and partly because their accident rate has been rising for pedestrians. As shown in Figure 3, their accident rate per crossing is higher than for the other types of crossing. In 2009, automatic crossings accounted for means of $52 \%$ of fatal accidents and $54 \%$ of fatalities at level crossings.

- At passive crossings (including footpath crossings), the number of fatal accidents per year has fallen over the long term. This is entirely due to the fall in the numbers of such crossings. Their mean accident rate remained remarkably constant at rather less than 1 per 1000 crossings per year, the majority being pedestrian accidents. Although their accident rate is low, the large number of passive crossings means that they accounted for substantial proportion of all accidents in 2009: $43 \%$ of fatal accidents and $41 \%$ of fatalities.

- The above counteracting trends for the different crossing types mean that, as shown in Figure 4 , the total numbers of fatal accidents at level crossings have remained almost unchanged for about 30 years at a mean of about 11 per year.

It follows that the principal reason why the number of fatal accidents has not declined since the early 1970s is the replacement of railway controlled by automatic crossings. However, it does not follow that this was a mistake, because automatic crossings have a number of important advantages over railway-controlled ones, which are generally the main alternative. The main advantages of automatic crossings are the following.

- They need no staff to operate them.

- They have much shorter cycle times than railway-controlled crossings, and thus cause less delay and capacity loss to road traffic. That is because railway-controlled crossings are interlocked with the signals. If a train is to run under clear signals, the time interval between the closure of the crossing to the road for an approaching train and the arrival of the train at the crossing is much longer for railway-controlled crossings than for automatic crossings. Thus the delay and the road capacity reduction at railway-controlled level crossings may be substantial.

Thus a balance has to be struck between the benefits of railway-controlled crossings and those of automatic ones. Intermediate types of crossing are possible with modern technology. It is possible that the retention of a relatively large number of railway-controlled crossings in Britain is a partial explanation for Britain's relatively good safety performance at level crossings. 


\section{Comparison of accidents at automatic level crossings and signalised road junctions}

There is evidence that a high proportion of level crossing accidents is associated with errors or violations by road users (for example, RSSB 2009). This is not surprising, given that most level crossing accidents occur at automatic or passive crossings, where the primary responsibility for safe use rests with road users. Railway operators tend to have a poor view of road users' behaviour at level crossings, and this is backed up by some well-known video clips of very dangerous behaviour by road users. Nevertheless, it is not clear whether road user behaviour is worse on at level crossings than on the roads generally.

This section presents a small piece of data to address this by comparing the fatal accident and fatality rates at automatic rail level crossings with their nearest road equivalent, signalised intersections. Table 8 gives data on the numbers of intersections/ crossings, and fatal accidents and fatalities at these locations in Great Britain in 2005. The rail data are the modelled estimates of the means for 2005 from the fitted model in section 4 . The road fatality data (121 fatal accidents; 126 fatalities) are taken from a special table produced for the writer by the Department of Transport (DfT) from the official road fatality data (DfT, annual). The number of signalised road intersections is based on an estimate by the County Surveyors' Society of 12,300 in 2000, increased by 3\% per year to 2005 (DfT, personal communication).

The bottom two lines of Table 8 show that the estimated fatal accidents and fatalities per intersection or crossing were similar.

Table 8: Fatal accidents and fatalities at automatic level crossings and signalised road
\begin{tabular}{|lrr|}
\hline \multicolumn{1}{|c}{ intersections: Great Britain 2005 } & Road & Rail \\
Estimated number of signalised intersections/ & 14,300 & 762 \\
automatic crossings & & \\
Number of fatal accidents 2005 & 121 & 5.13 \\
Number of fatalities 2005 & 126 & 6.01 \\
Fatal accidents per 1000 intersections/crossings & 8.5 & 6.7 \\
Fatalities per 1000 intersections/crossings & 8.8 & 7.9 \\
\hline
\end{tabular}

\section{Conclusions}

This paper investigates fatalities and fatal accidents at level crossings in Great Britain over the 64-year period 1946 to 2009. The numbers of fatal accidents and fatalities per year fell by about 65 per cent in the first half of that period, but since then have remained more or less constant at about 11 fatal accidents and 12 fatalities per year. At the same time other types of railway fatality have fallen, so level crossings represent a growing proportion of the total. Nevertheless, Britain's level crossing safety performance remains good by international standards.

The paper classifies level crossing types into three groups: railway-controlled, automatic, and passive. At the beginning of the period all crossings were either railway controlled or passive. Automatic crossings were not introduced into Britain until the early 1960s, replacing other types, but many railway-controlled crossings remain. As in most countries, by far the largest numbers of crossings are passive; most of these are not on public roads, but on private roads, farms, and footpaths. The total number of crossings has fallen by about 75 percent over the period, due partly to rail route closures and partly to closures of individual crossings, with or without replacement by bridges.

The safety performance of the three types of crossings has been very different. Railway-controlled crossings are the best-performing crossing type, with falling fatal accident rates. Automatic crossings have higher accident rates per crossing than railway controlled or passive crossings, and the accident rates have not decreased. They have advantages over railway controlled crossings on public roads in 
not needing staff and imposing less delay on road users. Nevertheless, they are less safe, so a balance has to be struck between safety, cost and delay. Passive crossings are by far the most numerous, but many have low usage by road users. Their fatal accident rate has remained remarkably constant over the whole period at about 0.9 fatal accidents per 1000 crossings per year.

A principal reason why fatal accidents and fatalities have not fallen in the second half of the period as they did in the first half is the increase in the number of automatic crossings, replacing the safer railway controlled crossings on some public roads. However, it does not follow that this replacement was a mistake, because of the advantages of automatic crossings above.

Based on the trends for each type of crossing and for pedestrian and non-pedestrian accidents separately, in 2009 means of 5 per cent of fatal accidents were at railway controlled crossings, 52 per cent were at automatic crossings, and 43 per cent were at passive crossings. Fatalities had similar proportions. About 60 per cent of fatalities were to pedestrians.

A simple comparison of automatic railway level crossings and signalised road intersections found that in 2005 the numbers of fatalities per 1,000 crossings or intersections were similar.

\section{Appendix 1}

The results in Section 4 of the paper are based on the assumption that the numbers of accidents are Poisson-distributed, even though they are 'overdispersed'. A common alternative to the Poisson distribution is to assume that the data have a negative binomial distribution. Table 9 gives results for the negative binomial distribution corresponding to those for the Poisson distribution in Table 6 . There is no absolute measure of goodness of fit for the negative binomial distribution corresponding to the scaled deviance, but the differences in minus twice the log likelihoods between the model variants have the same properties as the differences in the scaled deviances. On this basis model variant (e) remains the best fitting variant, and all significance tests lead to the same conclusions. The right-hand column of Table 9 shows that the parameter estimates with the negative binomial are close to those with the Poisson distribution; the standard errors are somewhat larger.

Table 9: Statistical results from fitting Negative Binomial log-linear models to the accident data

\begin{tabular}{|c|c|c|c|}
\hline $\begin{array}{l}\text { Variant of } \\
\text { model }\end{array}$ & $\begin{array}{l}\text { Degrees } \\
\text { of } \\
\text { freedom }\end{array}$ & $\begin{array}{l}\text { Difference } \\
\text { in - } 2 L L^{*} \\
\text { from (a) }\end{array}$ & $\begin{array}{l}\text { Estimate of trend parameter (standard error in } \\
\text { brackets) }\end{array}$ \\
\hline (a) No trend & 66 & 0 & Assumed zero for all types of crossing and accidents \\
\hline $\begin{array}{l}\text { (b) Common } \\
\text { trend }\end{array}$ & 65 & -7.2 & $-0.80 \%(0.30 \%)$ pa for all types of crossing and accidents \\
\hline $\begin{array}{l}\text { (c) Separate } \\
\text { trends for } \\
\text { accident types }\end{array}$ & 64 & -18.2 & $\begin{array}{l}-0.03 \%(0.35 \%) \text { pa for pedestrian accidents } \\
-2.01 \%(0.48 \%) \text { pa for non-pedestrian accidents }\end{array}$ \\
\hline $\begin{array}{l}\text { (d) Separate } \\
\text { trends for LC } \\
\text { types }\end{array}$ & 63 & -24.9 & $\begin{array}{l}-2.50 \%(0.56 \%) \text { pa for railway-controlled crossings } \\
+1.55 \%(0.91 \%) \text { pa for automatic crossings } \\
-0.33 \%(0.33 \%) \text { pa for passive crossings }\end{array}$ \\
\hline $\begin{array}{l}\text { (e) Separate } \\
\text { trends for LC } \\
\text { types and } \\
\text { accident types }\end{array}$ & 60 & -42.2 & $\begin{array}{l}-1.95 \%(0.63 \%) \text { pa for peds at controlled crossings } \\
-3.68 \%(1.00 \%) \text { pa for non-peds at controlled crossings } \\
+3.53 \%(1.43 \%) \text { pa for peds at automatic crossings } \\
+0.14 \%(1.10 \%) \text { pa for non-peds at automatic crossings } \\
+0.49 \%(0.37 \%) \text { pa for peds at passive crossings } \\
-1.75 \%(0.55 \%) \text { pa for non-peds at passive crossings }\end{array}$ \\
\hline
\end{tabular}




\section{List of abbreviations}

\begin{tabular}{|ll|}
\hline AHB & Automatic half barrier (level crossing) \\
ALCRM & All level crossings risk model \\
CSI & Common Safety Indicator \\
DfT & Department for Transport \\
ERA & European Railway Agency \\
GB & Great Britain \\
HMRI & Her Majesty's Railway Inspectorate \\
LC & Level crossing \\
Nped & Non-pedestrian accident \\
ORR & Office of Rail Regulation \\
Ped & Pedestrian accident \\
RSSB & Rail Safety and Standards Board \\
\hline
\end{tabular}

\section{References}

Austin, R D and J L Carson (2002). An alternative accident prediction model for highway-rail interfaces. Accident Analysis and Prevention 34(1), 31-42.

British Railways Board (1963). The reshaping of British Railways. HM Stationery office, London.

Department for Transport (annual). Reported Road Casualties Great Britain. TSO, London

Evans, A W (2003). Fatal Railway Accidents in Great Britain. Report to Rail Safety and Standards Board on research project T168. RSSB, London

Evans, A W (2007). Rail safety and rail privatisation in Britain. Accident Analysis and Prevention 39(3), 510-523.

European Railway Agency (2010). Railway safety performance in the European Union. ISBN 978-929205-013-9. ERA, Valenciennes, France.

Hall, S and P Van der Mark (2008). Level Crossings. ISBN (10) 071103308 0. Ian Allan, Hersham. UK.

Health and Safety Executive (1996). Railway Safety Principles and Guidance: Part 2, Section E:Guidance on level crossings. HS(G)153/6. ISBN 07176 0952 9. HSE Books.

Heavisides, J and J Barker (2008). Impact of traffic flow on level crossing risk. Paper presented at the $10^{\text {th }}$ World level Crossing Symposium, International Union of Railways, Paris.

HM Railway Inspectorate (annual). Railway Safety Statistical Report. Office of Rail Regulation, London. (Earlier years have other titles and other publishers).

Ministry of Transport (1968). Report of the public inquiry into the accident at Hixon level corssing on 6 January 1968. Cmnd 3706, Her Majesty’s Stationery Office, London.

Mok, S C and I savage (2005). Why has safety improved at rail-highway grade crossings? Risk Analysis 25(4), 867-879.

Rail Accident Investigation Branch (2009). Investigation into safety at user worked crossings. Report 13/2009, RAIB, Derby, UK.

Rail Safety and Standards Board (2004). Road vehicle level crossings special topic report. RSSB, London. 
Rail Safety and Standards Board (2006). The cost of level crossings - an international benchmarking exercise. Research Project T364, RSSB, London.

Rail Safety and Standards Board (2009). Annual safety Performance Report 2008. RSSB, London. (http://www.rssb.co.uk/sitecollectiondocuments/pdf/reports/ASPR\%202008.pdf)

Rail Safety and Standards Board (2010). Development of the All Level Crossing Risk Model: a History. Report prepared by A D Little. RSSB, London.

Stott, P F (1987). Automatic open level crossings: a review of safety. ISBN 0115508317 . Her Majesty's Stationery Office, London. 